\title{
Rapid Bridge Replacement: Processes, Techniques, and Needs for Improvements
}

\author{
Yong Bai, Ph.D., M.ASCE${ }^{1}$; and William R. Burkett, A.M.ASCE ${ }^{2}$
}

\begin{abstract}
The terrorist attack on September 11, 2001 and subsequent potential threats to the United States transportation systems have presented an urgent need to develop emergency response plans in order to quickly react to the possible consequences of an extreme event. Highway bridges, as critical components of the nation's transportation network, have received increased attention. To respond to the potential threats on highway bridges, a research project was conducted to identify rapid bridge replacement processes, techniques, and needs for improvements. To achieve the research objectives, the research team studied three cases of previous bridge replacements following extreme events. By studying these cases, the research team first sought to identify and expand on lessons learned and then addressed which actions did and did not work effectively under the incident circumstances. Using the lessons learned government agencies and engineering and construction communities could enhance their emergency response plans for future incidents. Next, the research team identified needed improvements so that the research community could investigate new technologies to advance current practices.
\end{abstract}

DOI: 10.1061/(ASCE)0733-9364(2006)132:11(1139)

CE Database subject headings: Bridge construction; Bridge design; Emergency services; Bridges, highway; New York; Oklahoma; Pennsylvania; Rehabilitation.

\section{Introduction}

The terrorist attacks on September 11, 2001, and subsequent potential threats to the United States transportation systems have presented an urgent need to develop emergency management plans in order to quickly react to the possible consequences of an extreme event. An extreme event includes terrorist attacks and man-made or natural disasters such as explosions, fires, floods, and earthquakes. Highway bridges, a critical component of the nation's transportation network, have been brought to close attention by government agencies. The reasons that bridges are key elements of the nation's transportation system are (Barker and Puckett 1997):

1. A bridge controls the capacity of the system;

2. A bridge is the highest cost per mile of the system; and

3. If a bridge fails, the system fails.

To respond to an extreme event, a developed emergency management plan must include four related components (Parsons Brinckerhoff 2002):

1. Mitigation: steps taken in advance to reduce the potential loss from an extreme event;

\footnotetext{
${ }^{1}$ Assistant Professor, Dept. of Civil, Environmental, and Architectural Engineering, The Univ. of Kansas, 1530 W. 15th St., 2150 Learned Hall, Lawrence, KS 66045 (corresponding author). E-mail: ybai@ku.edu

${ }^{2}$ Professor, Dept. of Engineering Technology and Civil Engineering, Texas Tech Univ., Lubbock, TX 79409. E-mail: randy.burkett@ coe.ttu.edu

Note. Discussion open until April 1, 2007. Separate discussions must be submitted for individual papers. To extend the closing date by one month, a written request must be filed with the ASCE Managing Editor. The manuscript for this paper was submitted for review and possible publication on October 10, 2005; approved on April 24, 2006. This paper is part of the Journal of Construction Engineering and Management, Vol. 132, No. 11, November 1, 2006. CASCE, ISSN 0733-9364/2006/11$1139-1147 / \$ 25.00$.
}

2. Preparedness: steps taken in advance to facilitate the response and recovery after an extreme event;

3. Response: steps taken during or immediately after an extreme event to save lives and property; and

4. Recovery: steps taken to restore the affected areas to their normal status.

Since September 11, 2001 several research projects have been conducted to identify the infrastructure's vulnerabilities and to help government agencies develop or update the emergency management plans with focus on mitigation, preparedness, response, and recovery. The American Association of State Highway and Transportation Officials (AASHTO) recognized the need to address the nation's vulnerability assessment requirements for highway transportation and sponsored the development of a guide for critical asset identification and protection (SAIC 2002). The guideline's authors divided vulnerabilities in highway transportation into the following three general categories:

1. The physical facilities themselves (e.g., bridges, tunnels, roadways, and interchanges);

2. The vehicles operating on the system; and

3. The information infrastructure that monitors and manages the flow of goods, vehicles, and people on the highway system. This guide provides a starting point to identify and mitigate the vulnerability of and consequences to highway transportation assets from terrorist threats or attacks. A companion document, "A guide to updating highway emergency response plans for terrorist incidents," also funded by AASHTO and developed in parallel with the previous guide, assists government agencies in preparing and executing a coordinated emergency response terrorist threats or attacks to the highway transportation system (Parsons Brinckerhoff 2002). Besides these two guides, AASHTO sponsored another research project titled "Design of highway bridges for extreme events," which was supervised by the $\mathrm{Na}$ tional Cooperative Highway Research Program (NCHRP). The 
Table 1. Brief Description of Bridge Cases

\begin{tabular}{|c|c|c|c|c|c|}
\hline $\begin{array}{l}\text { Case } \\
\text { number }\end{array}$ & Case title & Bridge structure & Incident & Major replacement tanks & $\begin{array}{l}\text { Replacement } \\
\text { duration }\end{array}$ \\
\hline 1 & $\begin{array}{l}\text { I-95 Chester Creek } \\
\text { Bridge, Pennsylvania }\end{array}$ & $\begin{array}{l}\text { Three-span steel girder } \\
\text { over water with concrete } \\
\text { deck and piers }\end{array}$ & $\begin{array}{l}\text { Gasoline tanker } \\
\text { impact with } \\
\text { fire on deck }\end{array}$ & $\begin{array}{l}\text { Replacement of steel } \\
\text { girders and concrete deck }\end{array}$ & $\begin{array}{l}\text { May 23- } \\
\text { June 29, } 1998\end{array}$ \\
\hline 2 & $\begin{array}{l}\text { I- } 87 \text { New York } \\
\text { Thruway Bridge, } \\
\text { New York }\end{array}$ & $\begin{array}{l}\text { One-span steel girder } \\
\text { over traffic with } \\
\text { concrete deck }\end{array}$ & $\begin{array}{l}\text { Gasoline tanker } \\
\text { impact with } \\
\text { fire under deck }\end{array}$ & Total bridge replacement & $\begin{array}{l}\text { October } 9,1997- \\
\text { February 26, } 1998\end{array}$ \\
\hline 3 & $\begin{array}{l}\text { I-40 Webbers Falls } \\
\text { Bridge, Oklahoma }\end{array}$ & $\begin{array}{l}\text { Four-span steel girder } \\
\text { over water with concrete } \\
\text { deck and piers }\end{array}$ & $\begin{array}{l}\text { Barge impacted } \\
\text { substructure }\end{array}$ & $\begin{array}{l}\text { Replacement of piers, } \\
\text { steel girders, and concrete deck }\end{array}$ & $\begin{array}{l}\text { May 26- } \\
\text { July } 29,2002\end{array}$ \\
\hline
\end{tabular}

objective of this research was to develop a design procedure for application of extreme event loads and combination loading to highway bridges (Ghosn et al. 2003).

State Departments of Transportation (DOTs) also initiated efforts to investigate and develop methods to lessen the impact of terrorist attacks and other extreme events on their transportation infrastructure. A pooled-fund research project, led by the Texas Department of Transportation, entitled "Rapid bridge replacement techniques," was conducted to identify rapid bridge replacement processes, techniques, and needs for future improvement. One of the tasks associated with this research project was to conduct several case studies of previous bridge replacements following extreme events. The research team selected three cases to conduct detail case studies. They were the Interstate 95 (I-95) Chester Creek Bridge in Pennsylvania, the Interstate 87 (I-87) New York State Thruway Bridge in Yonkers, N.Y., and the Interstate 40 (I-40) Webbers Falls Bridge in Oklahoma. Table 1 provides a brief description of these cases. The reasons that these bridges were chosen were that they were critical components on the nation's major interstate highways and the incidents had significant impacts on the surrounding communities and the driving public. The paper presents the findings of this research project associated with these three detailed case studies.

The rest of the paper is organized as follows. First, the writers will state research objectives and methodology. Second, a general model that describes the rapid bridge replacement process will be outlined based on the three detailed case studies. Third, techniques that have been successfully utilized in the rapid bridge replacement will be presented. Fourth, the writers will outline the needs for future improvements in the area of rapid bridge replacement. These improvements shall be accomplished through further research efforts. Finally, the writers will present conclusions and recommendations.

\section{Research Objective and Methodology}

The objectives of the research were to identify rapid bridge replacement processes and techniques and assess needs for future improvements. Case study methodology was utilized to accomplish these objectives. By studying previous cases, the research team sought to identify and expand on lessons learned, address which actions did and did not work well given the circumstances of the incident, and propose future research to continuously improve the operations of rapid bridge replacement.

Case studies were conducted using a three-step approach. First, the research team reviewed the literature related to the cases. The literature included newspaper articles, conference and journal papers, technical reports, and web sites. Second, the re- search team interviewed key personnel who were involved in the case via the telephone. These people represented state DOTs, design firms, contractors, and material suppliers. In the telephone interviews, the personnel were asked a series of questions regarding their roles in the case and knowledge about the case. After the first two steps, the research team had developed initial impressions about each case and any unanswered questions were clearly outlined. The third step was to conduct a survey to gain knowledge about the previously unanswered questions and additional information related to each case. The survey questionnaire addressed five aspects: (1) contracting method; (2) engineering; (3) construction; (4) state DOT's support; and (5) material supplier and vendor. Findings of the case studies are presented in the following sections.

\section{Rapid Bridge Replacement Process}

A rapid bridge replacement process was identified based on three detailed case studies. A general model was developed to represent the process, shown in Fig. 1. The model includes three key elements: (1) major players, (2) major tasks, and (3) major decisions. Major players are parties such as state DOTs, design firms, contractors, and material suppliers and vendors, who have the responsibilities to conduct the bridge replacement tasks and make major decisions during the bridge replacement process. Major tasks of bridge replacement include traffic detour, bridge demolition, design, contract, and reconstruction. At each stage, major decisions need to be made, which have significant impacts on the outcomes of bridge replacement. For example, during the design stage, the most important decision is to establish whether the bridge shall be rebuilt using an identical structure or a new structure. If the decision is to use the identical structure, then the design work is simple if the original drawings and specifications are archived. The I-95 Chester Creek Bridge replacement was an example where the original design was utilized. In some cases, using the identical structure may not be the best way to replace a bridge quickly. This was the case for the I-40 Webbers Falls Bridge in Oklahoma. The bridge was hit by a towboat with two empty barges on May 26, 2002 and four spans were damaged. The original structure was a continuous haunched steel girder bridge with a 61-101-61 m (201-330-200 ft) main span combined with steel girder approach spans and a reinforced concrete deck, as shown in Fig. 2. After the incident, precast, prestressed concrete girders were utilized in lieu of the original steel approach girders in order to reduce the material delivery time (Bai et al. 2006).

During the replacement process, various engineering and construction techniques were employed to minimize impacts to the 


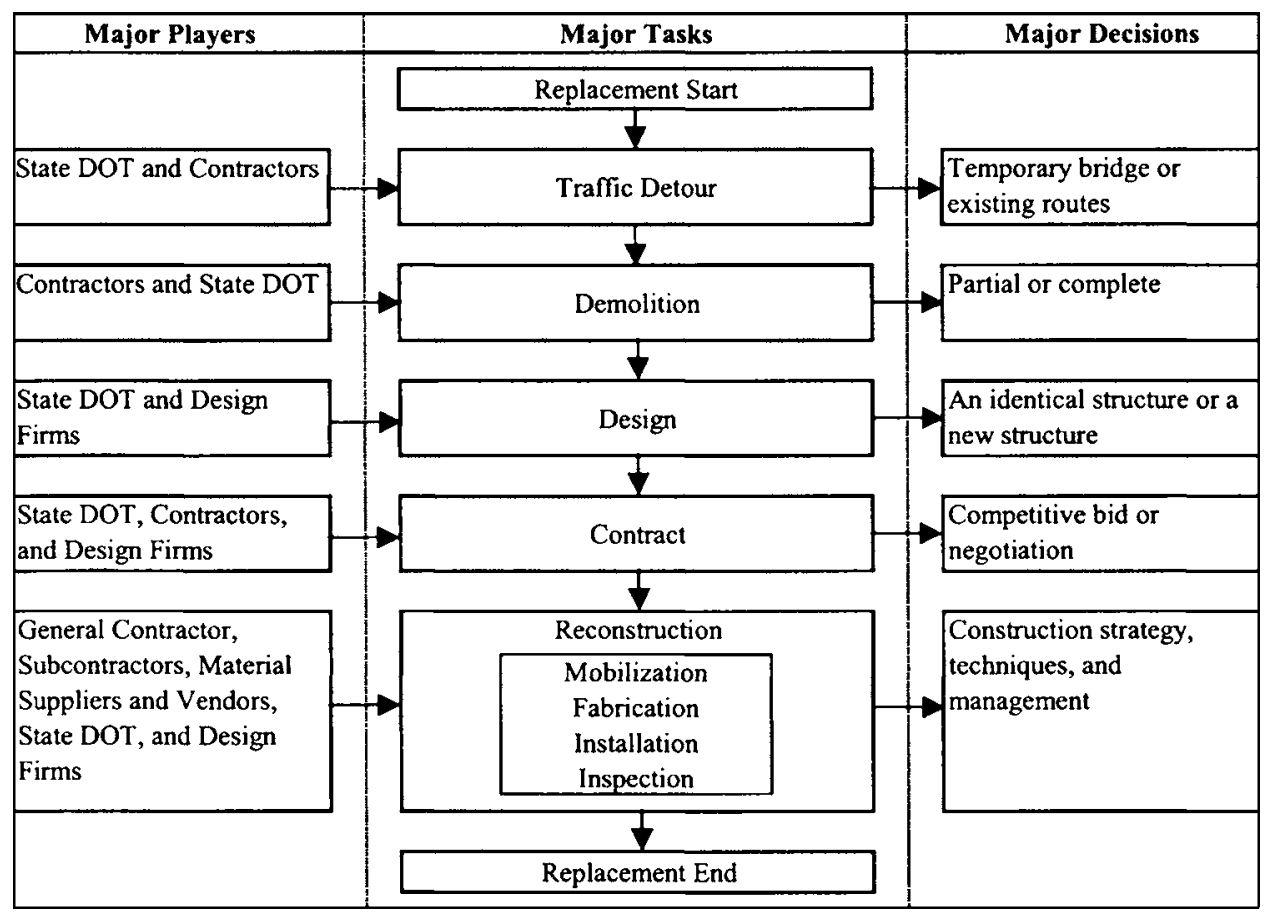

Fig. 1. General model for bridge replacement

traveling public and surrounding communities while accelerating the overall replacement schedules. These techniques are discussed in the next section.

\section{Rapid Bridge Replacement Techniques}

As mentioned before, major tasks of bridge replacement include traffic detour, demolition, design, contract, and reconstruction. Various techniques were utilized during the different stages on the three bridge replacements and were proven to be very effective.

\section{Traffic Detour}

Establishing temporary traffic detour routes for the traveling public is one of the most urgent tasks that state DOTs must perform immediately after an incident. These detour routes need to be available during the entire period of bridge replacement. There are three common ways to establish detour routes. The first

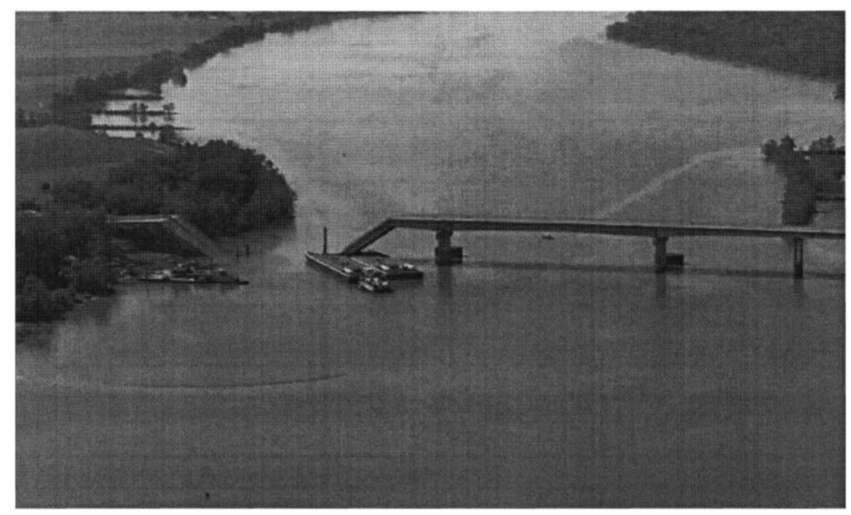

Fig. 2. Overview of damaged I-40 Webbers Falls Bridge method is to use undamaged portion of bridge as detour routes. Bridge engineers from the Pennsylvania Department of Transportation (PennDOT) evaluated the I-95 Chester Creek Bridge just after the accident and found that the southbound structure (three lanes) was unsafe due to severe damage caused by the fire and that the northbound structure (three lanes) was undamaged. Based on this scenario, PennDOT decided to modify three lanes of northbound bridge into four lanes to carry two lanes of traffic in each direction. The modified lane width was $3.35 \mathrm{~m}(11 \mathrm{ft})$ instead of a normal width of $3.66 \mathrm{~m}(12 \mathrm{ft})$ and a $64 \mathrm{~km} / \mathrm{h}$ $(40 \mathrm{~m} / \mathrm{h})$ speed limit was implemented and monitored closely by state police. Fig. 3 shows reconstruction of the I-95 southbound bridge deck and the four modified lanes on the northbound structure.

The second method to establish detour routes is to redirect traffic to existing roads in surrounding areas. This method was utilized for the I-40 Webbers Falls Bridge incident. The Oklahoma Department of Transportation (ODOT) established the detour routes for the traveling public using existing highways

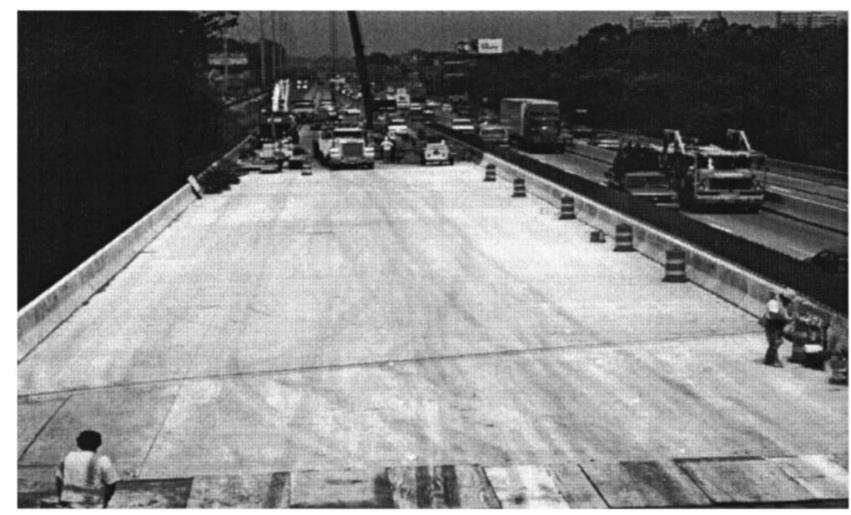

Fig. 3. Newly constructed I-95 bridge deck and detour lanes 


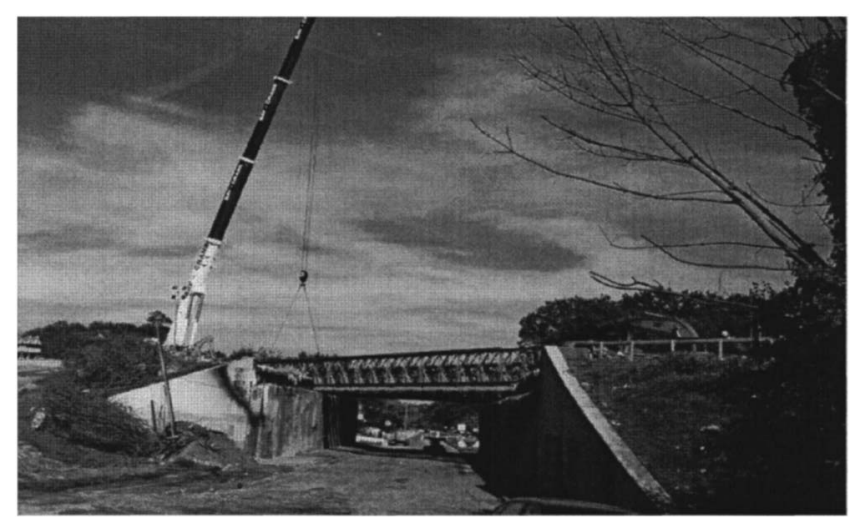

Fig. 4. Two temporary bridges on I-87

because some of the bridge spans had completely collapsed into the river. Due to the large increase of traffic volume on the detour highways, it was necessary for ODOT to take immediate action in the form of heavy maintenance, including overlays on portions of the detour highways, to prevent pavement failures that would endanger the traveling public (ODOT 2002). Several emergency maintenance contracts were issued to resurface highway pavements. In addition, ODOT inspected 42 bridges on the detour routes and performed maintenance work on two bridges.

The third method to establish detour routes is to install prefabricated temporary bridges. Shortly after the incident on I-87 Bridge in Yonkers, the New York State Thruway Authority (NYSTA) determined that the use of temporary bridges would be the fastest and best way to accommodate traffic while the permanent bridge was under reconstruction. Demolition of the damaged bridge started immediately to provide space for the erection of a pair of two-lane temporary bridges, one for southbound traffic and another for northbound traffic. These bridges, shown in Fig. 4, were prefabricated steel panel truss structures similar to the British Bailey Bridges that were developed during World War II for use in remote combat areas. The southbound temporary bridge was approximately $44.80 \mathrm{~m}(147 \mathrm{ft})$ long and the northbound bridge was about $47.24 \mathrm{~m}$ (155 ft) long. The bridges spanned over the existing abutments so that repair work on the permanent abutments could be done without interfering with the traffic above. Each bridge weighed more than $91 \mathrm{Mg}(100 \mathrm{t})$. A ten-man crew assembled the temporary bridges and installed them using stationary launch rollers and a crane. Stationary launch rollers were used to allow horizontal movement of the temporary bridges and the crane was utilized for vertical lifting of the cantilevered ends of each bridge. The temporary bridges were ready for use by the traveling public in only 11 days (NYSTA 1997a,b).

The selection of the most effective temporary detour method depends on the incident site conditions. There is no single method that fixes all situations. Using an undamaged portion of bridge as a detour route will slow down the normal traffic flows and cause congestion. Utilizing other highways as detour routes will increase the traffic volume on these highways and may cause early damage to pavements. In addition, people have to travel extra miles to reach their destinations, thus increasing the user costs and travel time. Installing prefabricated temporary bridges near the accident site can help maintain normal travel speed and traffic capacity while reducing the inconvenience to the traveling public. However, this option is not always feasible and usually takes more time to set up. No matter what method is used, the key success factor during this stage is to reestablish a reasonable traffic flow as quickly as possible.

\section{Demolition}

There are two major challenges during the demolition stage. One challenge is to demolish a partially damaged bridge without causing further damage to the remaining bridge structure. Another common challenge is to conduct underwater demolition. During the demolition of I-40 Webbers Falls Bridge, construction crews faced these two challenges simultaneously. ODOT awarded an $\$ 850,000$ lump sum, 16-day contract for demolition work necessary to remove the damaged sections of the bridge. The contractor would receive $\$ 50,000 /$ day bonus for each day it finished ahead of the schedule and penalized $\$ 50,000 /$ day for each day it finished late.

The demolition crews knocked down the remaining damaged piers first, and then began breaking up the concrete on the spans. Spans 1 and 2 were brought down using explosives and debris was removed from the site. Span 3, which had completely fallen into the river, had to be removed using underwater demolition. The underwater demolition work environment was hazardous due to poor visibility. Demolition of the damaged portion of Span 4 was the most challenging task. This span was partially damaged. One end rested on the barges and the other end was still attached to the undamaged bridge as shown in Fig. 2. The remainder of the bridge structure could have been further damaged if the crews had not been careful during demolition of this region. To prevent further damage, the barges were stabilized and constantly monitored for movement during demolition. Combinations of demolition devices, including a wrecking ball, explosives, concrete shears, and other cutting devices, were used to meet the different demolition needs at the site. The debris removed from the accident site was temporarily stored on a 5-acre site on the river's west bank from where it was then trucked or floated away.

For the Webbers Falls Bridge, the demolition work was accomplished on time. However, there is a need for the research community to develop new construction technology that could perpetually improve the underwater demolition operations. Future development should focus on productivity and safety. There is a great potential for continuous improvement in these two areas.

\section{Design for Rapid Bridge Replacement}

There are two major objectives during the design stage for rapid bridge replacement. One objective is to make sure that reconstruction of the bridge can be conducted quickly based on the design drawings and specifications. Another is to expedite the design process itself. The damaged bridge can be replaced using either an identical structure or a new structure. The decision maker has to consider which alternative can best deliver a quick and economical reconstruction of the bridge. After the incident on I-40, ODOT decided to use three precast, prestressed concrete girders in lieu of the original steel approach girders because it took less time to produce concrete girders.

To expedite the I- 87 bridge reconstruction and minimize impacts to the traveling public, the NYSTA decided to use the Inverset Bridge System (made by the Fort Miller Company) to replace the damaged bridge. A total of 12 inverset units (modular prestressed bridge units containing a combined superstructure and deck as a single unit) were utilized. Each inverset unit was fabricated to cover the entire span but provided only a portion of the 
bridge's width. They were installed side by side to complete the bridge's lateral dimension. Each modular unit was cast upside down with the steel I-beam supports on top and concrete deck cast on the bottom. After curing in a controlled inside environment, the completed unit was turned right side up and transported to the site for installation. At the site, the units were set using a crane onto the bridge abutments. Because the inverset units were produced inside a fabrication plant, winter weather had no impact on the production and delivery of the units. This was very critical to the reconstruction of the bridge during the cold season.

In addition to using new structural members, design engineers also allowed contractors to use the concrete maturity method to expedite bridge reconstruction. Concrete maturity is a method for determining real-time in-place concrete strength using internal temperature. As soon as the concrete reached $100 \%$ design strength and had a minimum of 3 days curing, concrete forms were permitted to be removed and moment loadings were allowed to be applied to the structure. The American Society for Testing and Materials (ASTM) Standard C 1074, "Standard practice for estimating concrete strength by the maturity method," specifies the concrete maturity method procedure. While utilizing this method speeds up the replacement process, the long-term impacts of maturity method on concrete components in the bridge have not been thoroughly investigated.

Techniques used to expedite the design process include: (1) offering incentive/disincentive to the design firms; (2) providing the original drawings immediately to the design firms; (3) having state DOT engineers on call $24 \mathrm{~h} /$ day, 7 days/week to quickly answer any questions that the designers might have; and (4) changing the normal state DOT's operational procedures to quickly review and approve design drawings and specifications. Under normal conditions, it would take several weeks for state DOTs to review design submittals.

\section{Contracting Practices}

It is critical to select contractors that have the resources and the knowledge to accomplish bridge reconstruction projects under emergency situations. Several contracting methods were used in the three case studies and all were found to be effective.

The NYSTA utilized the traditional competitive bid method to award the reconstruction contract to Felix Equities Inc. of Lincolndale, N.Y. The contract specified a $\$ 5,000 /$ day bonus/penalty for early/late completion with a $\$ 50,000$ cap for either scenario. The contractor received a $\$ 40,000$ bonus ( 8 days at $\$ 5,000 /$ day) for early completion of the project ("Fast and convenient repairs" 1998). The bridge reopened to the public on February 26, 1998; just $41 / 2$ months after the incident (NYSTA 1998). Under normal conditions, approximately 2 years to replace the damaged bridge (NYSTA 1991a,b).

The contract of the I-40 bridge reconstruction was awarded using the "A plus B" competitive bid method. "A plus B" method is one of the innovative project delivery methods that has been developed and implemented in the construction industry in recent years. One of the primary purposes of "A plus B" bidding is to encourage contractors to more actively manage their work schedule and, when necessary, to adopt innovative and aggressive scheduling and construction management processes that will shorten the construction duration and reduce the inconvenience to the driving public (Kent 2003). In the contract, "A" represents the cost of the project and " $\mathrm{B}$ " indicates the duration of the project. Using this method, the owner will evaluate the bid proposals based on not only the cost, but also the schedule. This is an ideal method for an emergency bridge reconstruction project since time is of the essence. In the bid document, ODOT specified 72 days as the maximum time allowed to complete the reconstruction. ODOT held a prebid meeting on Saturday, June 8, 2002. The potential bidders had an opportunity to visit the site to assess the bridge damage and site conditions. The contract was issued to Gilbert Central Corporation for $\$ 10.9$ million with a 57-day schedule on June 12, 2002 (FHWA 2002). The contract had a $\$ 6,000 /$ hour bonus/penalty clause, without cap either way. ODOT would pay Gilbert an additional $\$ 6,000$ for every hour it was ahead of the contract schedule and penalize the company $\$ 6,000 /$ hour for every hour it was behind schedule. The project finished at 10:00 a.m. on July 29, 2002, for a total time of 46 days and $16 \mathrm{~h}$, the fastest completion of a project of its type in United States history. Reconstruction was completed ahead of schedule by 10 days and $8 \mathrm{~h}$ and Gilbert received a $\$ 1,488,000$ bonus. ODOT also benefitted from the early completion of the project since traffic engineers estimated that the total user cost was $\$ 430,000 /$ day for every day that the bridge was not open. Under normal conditions, it if would have taken at least 6 months to finish the reconstruction.

Just an hour after the I-95 incident, the Governor of Pennsylvania declared it a disaster emergency. The declaration allowed government agencies such as PennDOT to expedite their response to the accident in order to protect public health and safety. The declaration set aside the normal government constraints, allowing agencies to hire, purchase, and contract without following standard government rules and regulations. The Secretary of PennDOT immediately awarded the replacement contract to Buckley \& Company, Inc., who built the original bridge and had previous success in a similar replacement project. Buckley was paid on a time-and-materials (force account) basis with markups specified in PennDOT's standard specifications PUB 408. Subcontractors were also paid on a time-and-materials basis and Buckley received an $8 \%$ markup on top of subcontractors' costs. All overtime wages were paid directly with the standard PennDOT markup of $40 \%$ applied to labor. Using established contracting documents, which in this case was PennDOT's standard specifications PUB 408, expedited the contract negotiation process and avoided future contract disputes. Because of the good weather, hard work, and quick delivery of supplies, the bridge was reopened to the public on June 29, 1998. Buckley continued to perform structural work underneath the bridge after traffic had been restored. All repair work was completed on Friday, July 3, 12 days ahead of the original target date of July 15 . Based on past experience, similar repair work would require approximately 6 months under normal conditions. Using conventional bid procedures, the entire repair process could have taken even longer. Officials from PennDOT stated that the reconstruction project cost less than the original $\$ 4,000,000$ estimate. Buckley received $\$ 500,000$ for overtime pay.

One of the lessons learned from these case studies is that the inclusion of an incentive/disincentive $(I / D)$ clause in a bridge reconstruction contract generally assists in shortening the contract completion time. The $I / D$ clause is a contract technique that monetarily rewards contractors for early completion and penalizes them for late completion of a contract. $I / D$ clauses are not appropriate for every construction contract but are typically reserved for projects where user costs are high and the impact on the driving public is severe. In addition, $I / D$ limits should not be arbitrary amounts but should be based on user costs and state highway agency costs associated with inspection and administration of the project. 


\section{Techniques for Rapid Bridge Reconstruction}

During the bridge reconstruction stage, the objective was to finish the reconstruction quickly while minimizing the inconvenience to the traveling public and surrounding communities. Several construction engineering and management techniques were implemented to achieve the objective. These techniques included: (1) use of various construction work schedules, (2) staged construction, (3) changing normal operational procedures, and (4) getting support from communities.

\section{Construction Work Schedules}

The use of various construction work schedules can have a significant impact in the rapid reconstruction of bridges. Beyond the standard 8:00 a.m. to 5:00 p.m. work schedule, there are three schedules that warrant discussion; 24-h construction, 12-h construction, and nighttime only construction. The choice of the appropriate work schedule can be written into the contract or left to the discretion of the contractor as he/she develops his/her cost estimate and work plan to execute the project within the restraints of the contract (time, cost, and incentives/disincentives). Issues that should be considered when selecting the appropriate construction work schedule include:

1. Increases in construction costs typically associated with accelerated construction schedules;

2. Decreases in user costs and public inconveniences associated with shorter out-of-service periods or with limited-peak traffic demand closures;

3. Availability of state DOT personnel for inspection and problem solving during off-duty hours;

4. Availability of materials and material deliveries during nonstandard hours; and

5. Loss of worker productivity, loss of quality control, and increased worker safety issues typically associated with accelerated or nighttime construction or extended work shifts.

Reconstruction projects, such as the I-40 and I-95 bridges, which were identified during the course of this research, show that accelerated work schedules can be used to complete projects in shorter periods of time, but they typically increase the overall construction cost of the projects. However, increases in construction cost are typically offset by corresponding decreases in user costs or actual state DOT costs associated with temporary traffic.

Utilization of a 24-h construction schedule is warranted when circumstances are severe enough to justify the increase in cost associated with its use. Special attention addressing quality control, inspection, change order approval, engineering or construction problem resolution, lighting, safety, worker fatigue, and material deliveries must be addressed as work continues $24 \mathrm{~h}$ /day, utilizing either three 8-h shifts or two 12-h shifts daily. In addition to the issues directly related to the construction process, other issues like noise, vibrations, and light that can be a nuisance to nearby property owners also have to be addressed when evening and nighttime construction is being utilized. Guidance for these issues is provided in a NCHRP report, "Mitigation of nighttime construction noise, vibrations, and other nuisances" (Schexnayder and Ernzen 1999). In addition, special requirements for nighttime lighting must be addressed. Guidance for issues related to nighttime lighting is provided by another NCHRP report, "Illumination guidelines for nighttime highway work" (Ellis et al. 2003).

Utilization of a 12-h construction schedule is warranted when circumstances are not severe enough to justify a $24-\mathrm{h}$ schedule, along with its significant cost increase, but critical enough that a standard 8-h day will not provide an acceptable estimated project completion schedule. Even though many of the cost increases associated with a 24-h schedule are not incurred with a 12-h schedule, they must be weighed against increased construction time, user cost, and traffic congestion that will be endured. In addition, many of the issues discussed above that require special attention during 24-h construction are eliminated or reduced during 12-h construction. Some portions of any given project may require accelerated or relaxed work schedules that vary within the project. During the demolition phase of the I-95 Chester Creek Bridge replacement project, time sequencing was not critical enough to warrant the increased cost associated with 24-h construction, so 12-h construction was used.

Utilization of nighttime construction is warranted when circumstances are severe enough to justify the increases in cost and coordination that are associated with its use. Nighttime only construction is commonly used for bridge deck replacement projects with high volume traffic where daytime construction would cause unacceptable traffic disruptions. During these projects, portions of the bridge deck are replaced each night during reduced traffic flow and are opened to traffic the next morning prior to rush hour traffic. This type of project typically has a heavy monetary penalty associated with any late reopening of the bridge in the morning. Key issues associated with nighttime construction that need to be addressed are discussed in the 24-h construction section above and are not repeated here.

\section{Staged Construction}

Staged construction, just as its name implies, is where bridge reconstruction is done in planned sequential stages, maintaining portions of the bridge in an operating condition for traffic while other portions are closed for replacement. Traffic can be maintained via an undamaged portion of the existing structure, an adjacent parallel structure, or via a temporary bridge on the original or adjacent alignment.

The I-87 New York Thruway Bridge used a staged construction approach to replace the fire damaged bridge. Once the initial damaged bridge was removed, two temporary prefabricated bridges were installed on a portion of the original site to carry the traffic flow while a portion of the bridge was reconstructed. Once the initial portion of the reconstructed bridge was ready for traffic, traffic was rerouted onto it, and one of the two temporary bridges was removed. Once the second portion of the reconstructed bridge was ready for traffic, traffic was rerouted onto it, and the last temporary bridge was removed, thus allowing reconstruction of the last portion of the bridge. Using staged construction techniques minimized the disruption and inconvenience to the traveling public and surrounding communities.

\section{Changing Normal Operational Procedures}

Rapid bridge replacement is not successful unless all parties involved in the process change their normal way of doing business. After the I-40 incident, the assistant bridge engineer for design from ODOT was on call $24 \mathrm{~h} /$ day, 7 days/week to answer any questions that the design firm had. ODOT also created a special construction residency at the project site. A 13-member team of inspectors was formed to oversee the reconstruction of the bridge. Some of the inspectors were retired ODOT employees. In addition to the site inspections, inspectors were sent to the steel fabrication shops to make sure that fabrication was done as designed and within specification. Under normal circumstances, ODOT probably would have only two inspectors assigned to a project. 
For the I-95 bridge project, the fabrication and delivery of the steel beams were the critical activities in the reconstruction process. To meet the schedule requirement, the steel fabricator had to reschedule other work and implemented a 24-h work schedule for the replacement project. The fabrication of nine, 20-24 m (65-80 ft) long girder segments, each standing $2 \mathrm{~m}$ (6 ft 8 in.) high, weighing $14-18 \mathrm{Mg}(15-20 \mathrm{t})$, was completed in only 10 days. This accomplishment was 7 days ahead of the original delivery date (Carey 1998). Normally, this amount of fabrication work would take 3-4 weeks to complete. To coordinate with steel fabricator's schedule, PennDOT also changed its normal operational procedures and conducted the PennDOT required inspections at the steel plant and fabrication shop.

\section{Community and Interagency Cooperation}

Support from communities has proved to be a critical factor that makes a bridge replacement project successful. For the I-40 bridge replacement, coordination among federal, state, and tribal governments was crucial to putting the bridge back into commission on the fast track. As the sole owner of the Arkansas Riverbed and Banks at Webbers Falls, the Cherokee Nation controls the land around the reconstruction site. From day one, the Cherokee Nation contributed land and manpower and facilitated the project by making work areas easily accessible to contractors (Cherokee Nation 2002). The Federal Highway Administration (FHWA) approved $\$ 3$ million in federal emergency relief funds to get the repair work started immediately (FHWA 2002). Throughout the replacement process, FHWA provided technical expertise and assistance to ODOT, particularly in the areas of bidding and contract administration. Both agencies worked together to streamline the bid review and approval procedures and get the reconstruction contract ready to put out for bid. ODOT also received technical help and cooperation from the US Army Corps of Engineers, US Coast Guard, and other state DOTs.

\section{Needs for Improvements}

Although the three bridge replacement projects studied in this research were all finished ahead of the original schedule with a good safety record, there are still areas for state DOTs, design firms, contractors, and material suppliers to consider for future improvements. Based on the case studies, three key elements for bridge replacement were identified including: (1) major players, (2) major tasks, and (3) major decisions. Major players are parties such as owners, design firms, contractors, and material suppliers who have the responsibilities to conduct the bridge replacement tasks and make major decisions during the bridge replacement process. Major tasks of bridge replacement include setting up temporary traffic detour, demolition of damaged structures, design, contract, and reconstruction. At each stage, major decisions need to be made, which have significant impacts on the outcomes of the bridge replacement. For example, during the design stage, the most important decision is to decide whether the bridge shall be replaced using an identical, modified, or completed new structure. If the decision is to use the identical structure, then the design work is simple if the original drawings and specifications are archived. In some cases, using the identical structure may not be the best way to replace a bridge quickly. This was the case for the I-87 Bridge in Yonkers, N.Y.

A question that must be considered is: under what conditions/ justifications shall the decision makers/bridge designers replace the damaged bridge using a different structure (e.g., using inverset units) instead of an identical structure? Making such a decision is difficult and people, who are capable of making the judgment, require considerable experience in the field. However, these people are not always available, nor do they always have the time to consult all possible references and review available data.

Bridge replacement is a complicated operation that involves many parties. It requires each party to make technical and management decisions at different stages in a very short period of time. Traditionally, each party makes decisions that best suit their interests, known as activity-level optimal. However, activity-level optimal may not lead to the best solution for the overall replacement project, known as project-level optimal. The major challenges of achieving project-level optimal for bridge replacement are communication and coordination among parties involved in the replacement process. Currently, there is no system that coordinates the different parties' tasks through gathering, processing, manipulating, storing, and distributing required information/data during the replacement process for decision-making purposes. Poor communication and coordination could result in cost overruns and inaccurate construction schedule forecasts. For example, nobody predicted that the replacement of I-95 Chester Creek Bridge would be ahead of schedule by 12 days until the very end of the project.

Because of these reasons, there is an urgent need to develop a knowledge-based information system for bridge replacement that integrates all parties' tasks during the bridge replacement process. The developed system will help the major players of bridge replacement to select optimal methods for traffic detour, demolition, bridge replacement design, contracting, and reconstruction. If successful, the system will not only improve the communication and coordination among parties, but also speed up the bridge replacement process and minimize impacts to the traveling public.

\section{Conclusions and Recommendations}

There were many factors contributing to the successful responses to the three incidents discussed in this paper. In order to document what can be learned from these extreme events, the research team conducted detailed case studies. During the studies, the research team reviewed literature including information posted on the web sites, interviewed people who were involved in the replacements of the bridges via the telephone, and performed surveys. Notwithstanding their terrible consequences, the three bridge tragedies provide useful lessons for government agencies, engineering and construction firms, and material suppliers, which must plan for enhanced responses in case of future incidents. The following conclusions are drawn from this research project.

1. Quick response to a bridge damage incident is the key to mitigating losses and easing any inconvenience to the traveling public;

2. Less time was required to design the new structure when original design drawings and specifications were immediately accessible to designers and state DOT engineers were available to answer questions;

3. It is critical to select design firms, contractors, and material suppliers that have the resources and the knowledge to accomplish replacement projects under emergency situations;

4. Pre-existing contracts and procedures sped up the contracting negotiation process and avoided future contract disputes;

5. Incentive and disincentive clauses in the contracts played a very successful role in motivating design firms, contractors, 
and material suppliers to finish their work on time or ahead of schedule;

6. Using prefabricated or modular elements avoids weather impact on production and delivery, thus, shortens the bridge reconstruction process;

7. Stage construction techniques minimize the disruption and/or inconvenience to the traveling public and the surrounding community during the replacement project;

8. Commitment of adequate resources for rapid bridge replacement, such as manpower, from all parties including state DOTs, design firms, contractors, and material suppliers, accelerates the replacement process;

9. Flexibility in state DOTs' and other government agencies' operational and contracting procedures expedited the reconstruction process;

10. The maturity method was used successfully to expedite the concrete construction process;

11. Community and interagency cooperation enabled the effective and smooth execution of the replacement projects;

12. Selective waiving or modification of standard state DOT construction specifications such as allowing estimating the concrete strength using the maturity method, when applicable, can significantly shorten construction schedules; and

13. The use of new and innovative construction materials, techniques, and work schedules can significantly shorten construction schedules.

Recommendations for continuous improvements were developed with construction and engineering communities and government agencies during the execution of this project. These recommendations also provide a guideline for future research effects in the subject of rapid bridge replacement. They are summarized as follows:

1. There is an urgent need for the research community to develop a knowledge-based information system that integrates major tasks of rapid bridge replacement such as traffic detour, demolition, design, contract, and reconstruction. If successful, the developed system will improve the communication and coordination among the parties involved in the bridge replacement process.

2. Options of using a competitive bid process to select a contractor to conduct the replacement work should remain open so that qualified contractors will have equal opportunity to participate in emergency replacement work. However, the duration of bidding process should be kept short.

3. More data are needed to better predict costs and schedules association with accelerated bridge reconstruction. It is recommended that parties who engage in rapid bridge replacement collect and compile cost and time data of past, current, and future projects for additional analysis.

4. There is a need to continue searching for new construction technology that could improve the reconstruction process. Areas such as underwater demolition and nighttime construction have great potential. Nighttime construction accelerates the replacement process and reduces the inconvenience of the traveling public. To fully utilize the benefits of this technique, several issues must be studied including sleep deprivation, fatigue, stress, poor visibility, irregular eating routine, and social/domestic issues.

5. To expedite the replacement projects, both state DOTs and private firms had to pull out some of their resources from existing design and construction projects. This action had negative impacts on existing projects. There is a need to address resource allocation issues in the emergency response plans.

This paper presents three real world emergency bridge replacement cases: the I-40 Webbers Falls Bridge in Oklahoma, the I-95 Chester Creek Bridge in Pennsylvania, and the I-87 New York State Thruway Bridge in Yonkers, N.Y. The lessons learned from these cases benefit government agencies such as state Departments of Transportation, who are responsible for development of the enhanced emergency response plans for highway bridges, and engineering and construction communities, who are responsible for design and reconstruction of the damaged bridges. The paper also identifies the areas that need to be improved in the emergency bridge replacement operations. These needed improvements become subjects for future research and development, which are the responsibilities of the research community. In addition, the methodology used for these case studies can be applied by the practitioners and researchers to a variety of construction related investigations in the future.

\section{Acknowledgments}

The writers would like to thank Mr. Rex Mackey of PennDOT; Mr. Robert Buckley, Mr. A Craig Hoogstraten, and Mr. David Warner of Buckley \& Company, Inc.; Mr. Steve Bussanmas of High Steel Structures, Inc.; Mr. Gregory Allen, Mr. George Raymond, and Mr. Bob Rusch of ODOT; Mr. Jim Poe of Gilbert Central Construction, Inc.; Mr. Tim Purkeypile of Poe \& Associates; Mr. Younus Samadzada of the New York State Thruway Authority; Mr. Peter Smith of the Fort Miller Company; and Mr. Phil Nash and Ms. Cindy Jones of Texas Tech University. A special thanks goes to state DOTs who provided financial support and guidelines for this research project. These DOTs include Texas, Georgia, Illinois, Iowa, Minnesota, Mississippi, New Jersey, Ohio, and South Carolina.

\section{References}

Bai, Y., Burkett, W. R., and Nash, P. T. (2006). "Lessons learned from an emergency bridge replacement project," J. Constr. Eng. Manage., 132 (4), 338-344.

Barker, R. M., and Puckett, J. A. (1997). Design of highway bridges, Wiley, New York.

Carey, K. E. (1998). "The quick fix," Sunday Times of Delaware County, July 12 .

Cherokee Nation (2002). "Cherokee Nation, ODOT pledge cooperation on I-40 Bridge." Cherokee Nation News Release, June 26, 〈http:// www.cherokee.org/NewsArchives/News2002Page.asp?ID = 532〉 (April 30, 2003).

Ellis, R. D., Jr., Amos, S., and Kumar, A. (2003). "Illumination guidelines for nighttime highway work." NCHRP Rep. No. 498, National Cooperative Highway Research Program, Washington, D.C.

"Fast, and convenient, repairs." (1998). "editorial" New York Times, March 12.

Federal Highway Administration (FHwA). (2002). "Accelerated bridge repairs: Meeting the challenge in Oklahoma." FOCUS 〈http:// www.tfhrc.gov/focus/aug02/01.htm $\rangle$ (March 22, 2003).

Ghosn, M., Moses, F., and Wang, J. (2003). "Design of highway bridges for extreme events." NCHRP Rep. No. 489, Transportation Research Board, Washington, D.C.

Kent, D. L. (2003). "Innovative contacting techniques that consider driver impact, Use of A+B bidding." U.S. Department of Transportation, Federal Highway Administration, September 〈http://ops.fhwa.dot.gov/ wz/workshops/accessible/Kent_MWZWB.htm〉 (June 12, 2004). 
New York State Thruway Authority (NYSTA). (1997a). "Governor Pataki opens temporary thruway bridges in Yonkers." News Release, October 20.

New York State Thruway Authority (NYSTA). (1997b). "Thruway announces Yonkers overpass plan." News Release, October 9.

New York State Thruway Authority (NYSTA). (1998). "Governor Pataki opens new thruway bridges at Yonkers." News Release, February 25.

Oklahoma Department of Transportation (ODOT). (2002). "I-40 bridge update: Day 29 of 57 construction days." Public Information, July 10, 〈http://www.okladot.state.ok.us/public-info/i40bridge-press/ july_10_Update.htm $\rangle$ (March 26, 2003).
Parsons Brinckerhoff (2002). "A guide to updating highway emergency response plans for terrorist incidents." Contractor's Final Rep., Rockville, Md.

Schexnayder, C. J., and Ernzen, J. (1999). "Mitigation of nighttime construction noise, vibrations, and other nuisances." NCHRP Synthesis of Highway Practice Rep. No. 218, National Cooperative Highway Research Program, Washington, D.C.

Science Applications International Corporation (SAIC). (2002). "A guide to highway vulnerability assessment for critical asset identification and protection." Contractor's Final Rep., Transportation Policy and Analysis Center, Vienna, Va. 